\title{
In vitro Effect of Withania somnifera, Mucuna pruriens and Pausinystalia johimbe on Hepatic Cytochrome P450 in Rat
}

\author{
Rajia Sultana and Md. Zakir Sultan \\ Centre for Advanced Research in Sciences (CARS), University of Dhaka, Dhaka-1000, Bangladesh
}

(Received: 7 March, 2018; Accepted: 23 May, 2018; Published: 31 July, 2018)

\begin{abstract}
The effect of Withania somnifera, Mucuna pruriens and Pausinystalia johimbe extracts on hepatic cytochrome P450 enzyme CYP3A4 activities was studied using rat liver microsomes. CYP3A4dependent testosterone $6 \beta$-hydroxylation activities were determined by ELISA. In the study, rats were treated with $W$. somnifera $(0.5 \mathrm{~g} / \mathrm{kg} / \mathrm{day}), M$. pruriens $(0.5 \mathrm{~g} / \mathrm{kg} / \mathrm{day})$ and $P$. johimbe $(0.25 \mathrm{~g} / \mathrm{kg} / \mathrm{day})$ extracts for 20 days. It was found that W. somnifera, $M$. pruriens and $P$. johimbe extracts showed potent to moderate inhibitory effect on CYP3A4 activities in rat liver microsomes, with $\mathrm{IC}_{50}$ values of 18.01 $\mathrm{ng} / \mathrm{mL}, 14.93 \mathrm{ng} / \mathrm{mL}$ and $21.03 \mathrm{ng} / \mathrm{mL}$, respectively.
\end{abstract}

Key words: Withania somnifera, Mucuna pruriens, Pausinystalia johimbe, cytochrome P450, inhibition.

\section{Introduction}

Herbal medicines are widely used around the world with the aim to obtain synergistic effects or decrease the side effects or toxicity (Pekthong et al., 2008; Nature, 2007). As alternative or complementary therapy in this world, it is gaining increasing popularity. It is used in many countries, including China, India, Bangladesh, Korea, Canada, Norway, the United Kingdom and other countries in Europe and South America, South Africa and the United States. The World Health Organization (WHO) estimates that 80 percent of the population of some Asian and African countries presently uses herbal medicine for some aspect of primary health care.

Withania somnifera, known as Ashwagandha, is a plant in the Solanaceae family. The roots, leaves and berries of the plant are most useful. The climates of India, Pakistan, Srilanka and Bangladesh are good for Ashwagandha cultivation. The main chemical constituents are alkaloids and steroidal lactones, tropine containing a hydroxyl group. The leaves contain the steroidal lactones. It is used as a medicinal herb in Ayurvedic medicine (MedlinePlus, 2017; Memorial, 2018).

Mucuna pruriens Linn. (Family: Fabaceae), known as Alkushi, is one of the popular medicinal plant in Africa and tropical Asia. It silage contains $11-23 \%$ crude protein, $35-40 \%$ crude fiber, and the dried beans contain $20-35 \%$ crude protein. The seeds of the plant contain about 3.1-6.1\% L-DOPA (L-3,4dihydroxyphenylalanine) with trace amount of alkaloids, serotonin, nicotine, mucunine, mucunadine, pruriendine, prurieninine, lecithin, steroids, and bufotenine (Rastogi et al., 1991a; Singh et al., 1995). M. pruriens was able to rescue sperm motility and count as well as possibly fertility in men suffering from infertility (Shukla et al., 2010). It is also used in Ayurvedic medicine in an attempt to treat diseases including Parkinson's disease (Katzenschlager et al., 2004).

Pausinystalia johimbe (Family: Rubiaceae), common name Yohimbe, is a plant species native to western and central Africa (Nigeria, Cabinda, Cameroon, Congo, Gabon, and Equatorial Guinea). Bark is used in extractions to make tinctures for

Correspondence to: Md. Zakir Sultan; E-mail: zakir.sultan@du.ac.bd; Phone; +88029661920-59, Extn. 4722 
traditional medicine and dietary supplements. The main active ingredient in the extract is yohimbine. It also contains other alkaloids with undefined properties as corynanthine, an alpha-1 adrenergic receptor blocker and raubasine (Beille, 2013; Doxey et al., 1984). Extracts from the bark of yohimbe are used as a general tonic and as an aphrodisiac (Beille, 2013). Side effects of using yohimbe may include high blood pressure, increased heart rate, headache, nausea, tremors and sleeplessness.

Cytochromes P450 (CYPs) are hemoproteins which use a variety of small and large molecules as substrates in enzymatic reactions (Gonzalez and Gelboin, 1992). CYPs enzymes are present in most tissues of the body, and play important roles to metabolize thousands of endogenous and exogenous chemicals including drugs. It is reported that CYPs involve about $75 \%$ of the total metabolism of drugs (Guengerich, 2008). Many drugs may increase or decrease the activity of CYPs by induction, or direct inhibition of the enzymes. This is a major source of adverse drug interactions, since changes in CYP enzyme activity may affect the metabolism and clearance of various drugs (Guengerich, 2008).

Humans have 57 genes and more than 59 pseudogenes divided among 18 families of cytochrome P450 genes and 43 subfamilies (Nelson et al., 2004). Cytochrome P450 3A4 (CYP3A4) is an important gene of the enzyme cytochrome P450, mainly found in the liver and in the intestine, which is responsible to oxidize small organic foreign molecules e.g. drugs. The main aim of the present study was to assess the effects of $W$. somnifera, $M$. pruriens and $P$. johimbe extract on microsomal hepatic P450 (CYP3A4) activities in vitro in rat liver microsomes.

\section{Materials and Methods}

Chemicals: Ethanol, $\mathrm{CHCl}_{3}, \mathrm{KCl}$ were purchased from Merck, Germany. EDTA and acetonitrile were purchased from Sigma-Aldrich, Germany. Tris-HCl (LOBA CHEMIE, India), testosterone (Atlas Medical, UK) and reduced nicotinamide-adenine dinucleotide phosphate (NADPH) (Origin- Sisco
Research Lab.) were also purchased. All other laboratory chemicals were used as the highest purity and from commercial suppliers.

Extraction of W. somnifera, M. pruriens and $P$. johimbe: W. somnifera and M. pruriens (seed) were purchased from the local market of Dhaka, Bangladesh and identified by a botanist. $P$. johimbe was a kind gift of S.B. Herbal \& Nutraceuticals, Rajshahi, Bangladesh. Dried raw materials of $W$. somnifera, M. pruriens were ground, soaked and stirred intermittently for 3-4 days in ethanol. The extraction of $P$. johimbe was carried out by dissolving powder of the plant in ethanol for 3 days. The extracts were filtered followed by drying using a rotary evaporator under reduced pressure at low temperature $\left(40^{\circ} \mathrm{C}\right)$ and yielded semisolid residues which were kept at $4^{\circ} \mathrm{C}$ until use.

Preparation of microsomes: In this study 20 female Wistar rats ( 8 weeks old) weighing about 200 $\mathrm{g}$ were purchased from Bangladesh Council of Scientific and Industrial Research (BCSIR), Dhaka, Bangladesh. Prior to commencement of the experiment, all the rats were acclimatized to the new environment for a period of one week. During the experiment period the rats were kept in a well ventilated animal house at room temperature of $25^{\circ} \mathrm{C}$. They were supplied with standard pellets and fresh drinking water. All the rats were kept in cage and maintained with natural $12 \mathrm{~h}$ light and dark cycle in the Animal House of the Institute of Food and Nutrition Science, University of Dhaka, Bangladesh. This study was conducted according to the Declaration of Helsinki. The rats were randomly assigned into four groups and 5 rats were taken in each group.

Group-I was treated with $W$. somnifera $(0.5$ $\mathrm{g} / \mathrm{kg} /$ day), Group-II was M. pruriens $(0.5 \mathrm{~g} / \mathrm{kg} /$ day), Group-III was $P$. johimbe $(0.25 \mathrm{~g} / \mathrm{kg} /$ day $)$ extracts for 20 days and Group-IV was control group. The rats were sacrificed $24 \mathrm{~h}$ after the last treatment. The liver was immediately removed, weighed and washed in cold homogenization buffer $(50 \mathrm{mM}$ Tris- $\mathrm{HCl}, 150$ $\mathrm{mM} \mathrm{KCl}, 2$ mM EDTA, pH 7.4). Then the liver was homogenized in $4 \mathrm{ml}$ buffer per $1.0 \mathrm{~g}$ of liver. The 
homogenates were submitted for centrifugation at $4000 \mathrm{rpm}$ for $30 \mathrm{~min}$ (Pekthong et al., 2008; Pekthong et al., 2009; Richert et al., 2002). Finally, microsomal samples containing supernatant collected and frozen at $-80^{\circ} \mathrm{C}$ until analysis.

CYP3A4 testosterone 6 $\beta$-hydroxylase assay: Testosterone $6 \beta$-hydroxylation was measured by slightly modified method described by Pearce $e t$ al. (1996). According to this method, hepatic microsomes $(100 \mu \mathrm{l})$ were incubated at $37^{\circ} \mathrm{C}$ with testosterone $(50.88 \mathrm{nM})$ and NADPH $(2 \mathrm{mM})$ for $1 \mathrm{~h}$. The reaction was stopped by adding $300 \mu \mathrm{l}$ ice-cold acetonitrile and the samples were kept at ice for 30 min. Then the samples were centrifuged at $4000 \mathrm{rpm}$ for $20 \mathrm{~min}$ and the supernatants were collected for analysis.

ELISA assay: For this assay 96 well plate for ELISA (LisaScan EM, Erba Mannheim, Germany) was used. According to Chen et al. (1991), $50 \mu \mathrm{l}$ of standards, samples and control microsomes were dispensed into appropriate wells. $100 \mu \mathrm{l}$ of TMB (tetramethyl benzidine) substrate was dispensed to each well and gently mix for $10 \mathrm{sec}$. After incubating at room temperature $\left(22^{\circ} \mathrm{C}\right)$ for $20 \mathrm{~min}$, the reaction was stopped by adding $100 \mu \mathrm{L}$ of stop solution (1 M sulfuric acid) to each well. After gently mixing 30 sec, all the blue color was changed to yellowish color and the absorbance were measured at $450 \mathrm{~nm}$ immediately with ELISA reader.

Determination of $I C_{50}$ : $\mathrm{IC}_{50}$ is a measurement of the effectiveness of a compound in inhibiting biochemical processes and biological functions. According to the FDA (http://www.fda.gov), $\mathrm{IC}_{50}$ is the concentration of a particular drug or other substance/or inhibitor that is required to inhibit the biological process for $50 \%$ inhibition in vitro.

Inhibition of a drug in percent (I \%) were calculated as follows:

$$
\text { I \% }=\left(1-\mathrm{A}_{\text {Sample }} / \mathrm{A}_{\text {Blank }}\right) \times 100
$$

Here, $\mathrm{A}_{\text {blank }}=$ the absorbance of the blank (control)

$\mathrm{A}_{\text {Sample }}=$ the absorbance of the sample

Concentration of $W$. somnifera, $M$. pruriens and $P$. johimbe extracts providing $50 \%$ inhibition $\left(\mathrm{IC}_{50}\right)$ was calculated from the graph plotted inhibition percentage against extract concentration. The equation of the $\mathrm{IC}_{50}$ is given below:

$$
\mathrm{IC}_{50}=[(50-\mathrm{A}) /(\mathrm{B}-\mathrm{A})] \times(\mathrm{D}-\mathrm{C})+\mathrm{C}
$$

Where, $\mathrm{A}=$ the first point on the curve, expressed in percent inhibition, that is less than $50 \%$

$\mathrm{B}=$ the first point on the curve, expressed in percent inhibition, that is greater than $50 \%$ or equal to $50 \%$

$\mathrm{C}=$ the concentration of inhibitor that gives $\mathrm{A} \%$ inhibition

$\mathrm{D}=$ the concentration of inhibitor that gives $\mathrm{B} \%$ inhibition.

Statistical analysis: Statistical analysis was conducted by the general procedures of IBM SPSS Statistics 20, IBM Corporation. The significance of the difference between the groups was assessed by one-way ANOVA. The level of significance was evaluated at $\mathrm{p}$-value $<0.05$.

\section{Results and Discussion}

Effect of W. somnifera, $M$. pruriens and $P$. johimbe on CYP3A4 activities: The absorbencies of standard testosterone obtained from ELISA were plotted in a calibration curve to get the concentration of inhibition of samples (Figure 1). W. somnifera, $M$. pruriens and $P$. johimbe extracts were found to be inhibitory activity of CYP3A4. The $\mathrm{IC}_{50}$ values of $W$. somnifera, $M$. pruriens and $P$. johimbe extracts were found as $18.01 \mathrm{ng} / \mathrm{mL}, 14.93 \mathrm{ng} / \mathrm{ml}$ and $21.03 \mathrm{ng} / \mathrm{mL}$, respectively (Figure 2). These values exhibited higher degrees of inhibition that indicating the binding of the inhibitor (drugs) to the enzyme (CYP3A4).

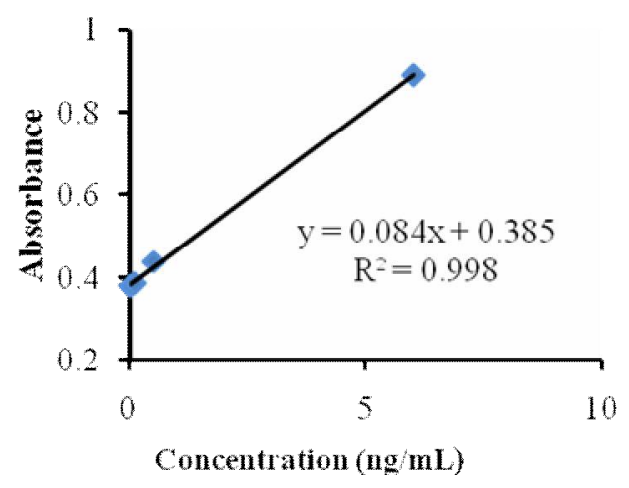

Figure 1. Standard calibration curve. Here, $n=3$ 
Cytochrome P450 (CYP) 3A4 is the most abundant human cytochrome enzyme. It plays central roles in the metabolism of xenobiotics including drugs, endogenous compounds and herbal component as effective substrates (Coon, 2005). The expression of individual CYPs is regulated by both endogenous factors and foreign compounds including drugs and natural compounds. The CYP substrates like both endogenous and exogenous compound can lead to pharmacokinetic interactions. When two or more drugs are administered at the same time, CYPs enzyme inhibition may contribute to decrease in one of the drug clearances due to drug-drug interaction and decrease in the formation of pro-dugs reactive metabolites, which can lead to decrease in the pharmacological effect of drug metabolism. However, the decrease in drug metabolism rate will increase drug toxicity (Jamal et al., 2010; Wienkers et al., 2005).

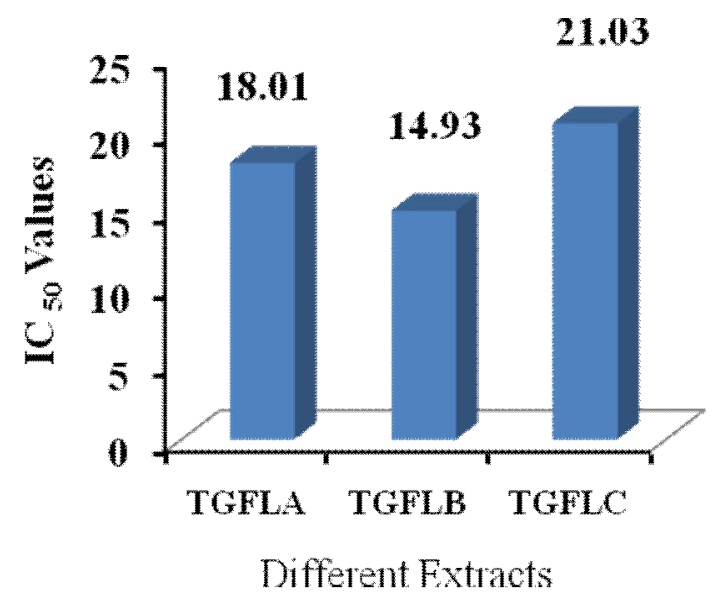

Figure 2. $\mathrm{IC}_{50}$ values of Different Drug on CYP3A4mediated activities in rat liver microsomes (TGFLA= treated with $W$. somnifera, TGFLB $=$ treated with $M$. pruriens and TGFLC $=$ treated with $P$. johimbe).

\section{Conclusion}

CYP3A4 is the largest single portion of the CYP450 protein and responsible for the metabolism of a wide variety of drugs. From the present in vitro study on rat liver microsomes, it was found that $W$. somnifera, $M$. pruriens and $P$. johimbe extracts showed moderate inhibition with $\mathrm{IC}_{50}$ values of 18.01 $\mathrm{ng} / \mathrm{mL}, 14.93 \mathrm{ng} / \mathrm{mL}$ and $21.03 \mathrm{ng} / \mathrm{mL}$, respectively of CYP3A4 of hepatic microsomes of rats. Based on the findings it was concluded that $W$. somnifera, $M$. pruriens and $P$. johimbe extracts were found to inhibit the catalytic activities of CYP3A4 in human also.

\section{Acknowledgement}

The authors would like express their gratitude to authority of the Centre for Advanced Research in Sciences (CARS), University of Dhaka, Dhaka-1000, Bangladesh for providing the financial support. The authors also express their gratitude to SB Lab, Rajshahi, Bangladesh, for providing gift sample of Pausinystalia johimbe. The authors express their thanks to Kanik Kumar Sarker for helping in the present work.

\section{References}

Beille, P.E. 2013. Scientific opinion on the evaluation of the safety in use of yohimbe (Pausinystalia yohimbe). Euro. Food Safety Auth. J. 11, 3302. DOI: 10.2903/j.efsa.2013.3302. https://doi.org/10.2903/j.efsa.2013.3308

Chen, A., Bookstein, J.J. and Meldrum, D.R. 1991. Diagnosis of a testosterone-secreting adrenal adenoma by selective venous catheterization. Fertil. Steril. 55, 1202-1203.

Coon, M.J. 2005. Cytochrome P450: nature's most versatile biological catalyst. Annu. Rev. Pharmacol. Toxicol. 45, 1-25.

Doxey, J.C., Lane, A.C., Roach, A.G. and Virdee, N.K. 1984. Comparison of the alpha-adrenoceptor antagonist profiles of idazoxan (RX 781094), yohimbine, rauwolscine and corynanthine. NaunynSchmied. Arch. Pharmacol. 325, 136-144.

Gonzalez, F.J. and Gelboin, H.V. 1992. Human cytochromes P450: evolution and cDNA-directed expression. Env. Health Pers. 98, 8185. PMC 1519618 $\square$. PMID 1486867.

Guengerich, F.P. 2008. Cytochrome P450 and chemical toxicology. Chem. Res. Toxicol. 21, 70-83, DOI: $10.1021 / \mathrm{tx} 700079 \mathrm{z}$

http://www.fda.gov/ohrms/dockets/ac/00/slides/3621s1d/sl

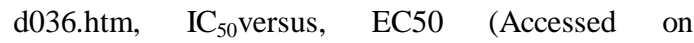
20/07/2018). 
Jamal, P., Barkat, A.A. and Amid, A. 2010. Distribution of phenolics in various Malaysian medicinal plants. J. Appl. Sci. 10, 2658-2662.

Katzenschlager, R., Evans, A., Manson, A., Patsalos, P.N., Ratnaraj, N., Watt, H., Timmermann, L., Van Der Giessen, R. and Lees, A.J. 2004. Mucuna pruriens in Parkinson's disease: a double blind clinical and pharmacological study. J. Neurol. Neurosurg. Psychiatry 75, 1672-1677.

MedlinePlus, US National Library of Medicine, 26 June 2017. Ashwagandha. Retrieved 21 December 2017. https://medlineplus.gov/druginfo/natural/953.html

Memorial Sloan Kettering Cancer Center, New York City, 13 April 2018. Ashwagandha. Retrieved 26 May 2018. https://www.mskcc.org/cancer-care/integrativemedicine/herbs/ashwagandha

Nature, 2007. Hard to swallow. 448, 105-106. DOI: https://doi.org/10.1038/448106a. (http://www.nature. com/nature/ journal/v448/n7150/full/448106a.html).

Pearce, R.E., McIntyre, C.J., Madan, A., Sanzgiri, U., Draper, A.J., Bullock, P.L., Cook, D. C., Burton, L.A., Latham, J., Nevins, C. and Parkinson, A. 1996. Effects of freezing, thawing, and storing human liver microsomes on cytochrome P450 activity. Arch. Biochem. Biophys. 331, 145-169.

Pekthong, D., Blanchard, N., Abadie, C., Bonet, A., Heyd, B., Mantion, G., Berthelot, A., Richert, L.and Martin, H. 2009. Effects of Andrographis paniculata extract and andrographolide on hepatic cytochrome P450 mRNA expression and monooxygenase activities after in vivo administration to rats and in vitro in rat and human hepatocyte cultures. Chem. Biol. Interact. 179, 247-255.
Pekthong, D., Martin, H., Abadie, C., Bonet, A., Heyd, B., Mantion, G. and Richert, L. 2008. Differential inhibition of rat and human hepatic cytochrome P450 by Andrographis paniculata extract and andrographolide. J. Ethnopharmacol. 115, 432-440.

Rastogi, R.P. and Mehrotra. B.N. 1991a. Compendium of Indian medicinal plants. Vol. I. (1960-1969). Central Drug Research Institute, Lucknow and Publications and Information Directorate, New Delhi.

Richert, L., Binda, D., Hamilton, G., Viollon-Abadie, C., Alexandre, E., Bigot-Lasserre, D., Bars, R., Coassolo, P. and LeCluyse, E. 2002. Evaluation of the effect of culture configuration on morphology, survival time, antioxidant status and metabolic capacities of cultured rat hepatocytes. Toxicol. in Vitro, 16, 89-99.

Shukla, K. K., Mahdi, A. A., Ahmad, M. K., Jaiswar, S. P., Shankwar, S. N., and Tiwari, S. C. (2010). Mucuna pruriens reduces stress and improves the quality of semen in infertile men. Evidence-Based Comp. Alter. Med. $\square: e C A M, 7, \quad$ 137-144. http://doi.org/10.1093/ ecam/nem171.

Singh, B.M., Srivastava, V.K., Kidwai, M.A., Gupta, V. and R. Gupta, 1995. Aloe, psoralea and mucuna. p. 515-525. In: Advances in horticulture (Chadha, K.L. and Gupta, R. eds.), Vol. 11, Medicinal and aromatic plants. Malhotra Publ, House, New Delhi.

Wienkers, L.C. and Heath, T.G. 2005. Predicting in vivo drug interactions from in vitro drug discovery data. Nat. Rev. Drug. Discov. 4, 825-833. 